\section{MINIMISE THE PRODUCTION OF CONTAMINATED AEROSOLS}

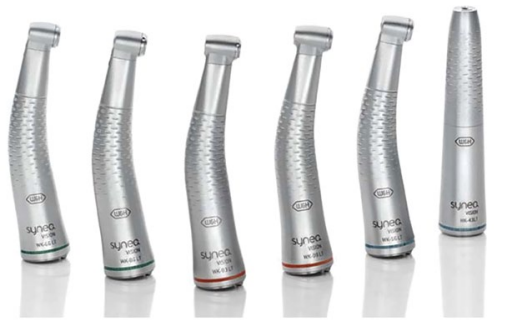

To support dental professionals, W\&H dental turbines offer features to minimise the production of contaminated aerosols in practice.

These handpieces feature a patented hygiene head with an anti-retraction system that is designed to limit the number of aerosols being sucked back into the turbine as the rotor slows to a stop.

Dental turbines from W\&H have also been optimised with an anti-retraction valve within the turbine itself, which prevents the backflow of potentially contaminated water via the turbine's waterlines to the central water supply system.

This facilitates the highest infection control standards for ultimate peace-ofmind among both staff and patients.

Discover the full range of W\&H handpieces via the website today.

To find out more visit www.wh.com/ en_uk, call 01727874990 or email office. uk@wh.com.

\title{
TOOTHBRUSHING NEEDN'T BE DIFFICULT
}
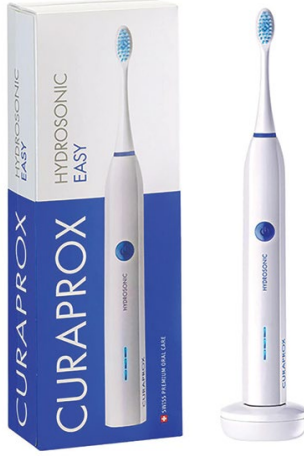

Curaprox has made toothbrushing simpler with the Hydrosonic Easy.

Offering three powerful cleaning modes, this electric toothbrush comes with two teardropshaped brush heads with ultra-soft CUREN filaments. The ergonomic design of these brush heads not only ensures each tooth is effectively enveloped, but that all areas of the oral cavity can also be accessed easily.

Once activated, the Hydrosonic Easy produces a hydrodynamic cleaning effect, whereby the movements produced by the device set the water, saliva and toothpaste in motion. This enables the fluids to remove plaque, food particles and other debris from interdental spaces and other notoriously hard-to-reach areas.

Help patients simplify oral care by recommending the Hydrosonic Easy today.

For more information call 01480 862084, email info@curaprox.co.uk or visit www.curaprox.co.uk.

\section{SIMPLE CHANGES}

The recipe for better oral health involves making small changes - encourage your patients to think of what they are adding, in order to gain benefits.

When the bigger picture is generally good, it is easier to find a balance and stick with new habits.

Something as simple as changing their toothpaste can have an impact. From Arm \& Hammer is a range of toothpastes with baking soda added to their formulations, which has been clinically recognised to enhance powerful plaque removal.
With an optimum daily cleaning routine and as part of a sensible approach to oral care, patients will enhance their general health and wellbeing.

Discover Arm \& Hammer toothpastes there are also formulations for sensitive teeth and for safe, effective whitening - and your patients will enjoy the benefits.

For more information about the carefully formulated Arm \& Hammer's toothpaste range, visit https://www.armandhammer.co.uk/ or email: ukenquiries@churchdwight.com.

Arm \& Hammer's oral healthcare products are available at Boots, Superdrug, Sainsbury's, Tesco, Asda and Morrisons throughout the UK.
COMPLETE SURFACE DISINFECTION IN JUST ONE HOUR

In normal cleaning routines, it's easy to miss hard to reach places - but these areas also harbour pathogens.

The AIRGENE

CE Airborne Surface

Disinfectant from

Eschmann ensures every surface, even the hard to reach areas, are effectively disinfected.

Its unique design means that a cloud of disinfectant fills an area of $40 \mathrm{~m}^{3}$ in just one minute, and an hour is all it takes to completely eliminate all airborne and surface pathogens as well as any odours caused by bacteria.

Independently tested under EN protocols (including EN 14476) and proven to be $99.99 \%$ effective against Coronavirus, AIRGENE CE Airborne Surface Disinfectant is a powerful addition to your usual cleaning routine, meaning no surface goes untreated!

Find out more today.

For more information on the highly effective and affordable range of infection control products from Eschmann, visit www.eschmann.co.uk or call 01903 875787.

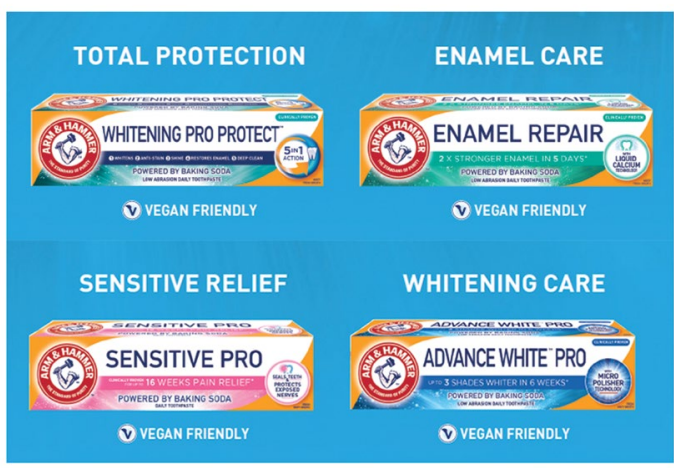

\section{Reference}

1. Bosma M-L, Milleman K R,

Akwagyiram I, Targett D, Milleman J L. A randomised controlled trial to evaluate the plaque removal efficacy of sodium bicarbonate dentifrices in a single brushing clinical model. $B D J$ Open 2018; 4: 17037. doi: 10.1038/ s41405-018-0003-7. 